\title{
Article \\ Life Prediction Model of Mineral Admixture Cement Based-Materials under Early Age $\mathrm{CO}_{2}$-Erosion
}

\author{
Saisai Wang ${ }^{1}$, Jian Chen ${ }^{1}$ and Xiaodong Wen ${ }^{1,2, *}$ \\ 1 School of Architecture and Transportation Engineering, Ningbo University of Technology, \\ Ningbo 315211, China; wss@nbut.edu.cn (S.W.); ecobmlab@163.com (J.C.) \\ 2 Zhejiang Engineering Technology Research Center of Civil Engineering Industrialized Construction, \\ Ningbo University of Technology, Ningbo 315211, China \\ * Correspondence: wenxiaodong@nbut.edu.cn; Tel.: +86-574-87611231; Fax: +86-574-87081278
}

Citation: Wang, S.; Chen, J.; Wen, X. Life Prediction Model of Mineral Admixture Cement Based-Materials under Early Age $\mathrm{CO}_{2}$-Erosion. Coatings 2021, 11, 413. https:// doi.org/10.3390/coatings11040413

Academic Editor: Andrea Nobili

Received: 8 February 2021

Accepted: 30 March 2021

Published: 1 April 2021

Publisher's Note: MDPI stays neutral with regard to jurisdictional claims in published maps and institutional affiliations.

Copyright: (c) 2021 by the authors. Licensee MDPI, Basel, Switzerland. This article is an open access article distributed under the terms and conditions of the Creative Commons Attribution (CC BY) license (https:/ / creativecommons.org/licenses/by/ $4.0 /)$.

\begin{abstract}
Most of the existing models of structural life prediction in early carbonized environment are based on accelerated erosion after standard 28 days of cement-based materials, while cement-based materials in actual engineering are often exposed to air too early. These result in large predictions of the life expectancy of mineral-admixture cement-based materials under early $\mathrm{CO}_{2}$-erosion and affecting the safe use of structures. To this end, different types of mineral doped cement-based material test pieces are formed, and early $\mathrm{CO}_{2}$-erosion experimental tests are carried out. On the basis of the analysis of the existing model, the influence coefficient of $\mathrm{CO}_{2}$-erosion of the mineral admixture $K_{m}$ is introduced, the relevant function is given, and the life prediction model of the mineral admixture cement-based material under the early $\mathrm{CO}_{2}$-erosion is established and the model parameters are determined by using the particle group algorithm (PSO). It has good engineering applicability and guiding significance.
\end{abstract}

Keywords: $\mathrm{CO}_{2}$ erosion; mineral admixture; early stage; prediction model; evaluation

\section{Introduction}

Erosion of rebar or embedded metal in cement-based materials caused by carbonization is one of the primary reasons of degradation of durability of engineering structures in the atmospheric environment, so carbonization analysis is important for evaluating the service life of engineering structures. In the natural environment, carbonization of cement-based materials is a slow process. In order to shorten the test cycle and improve the test efficiency, domestic and overseas researchers accelerate carbonization by improving the concentration of $\mathrm{CO}_{2}$. According to the Testing Methods of the Long-term Performance and durability Performance of Ordinary Concrete (GB/T 50082), the volume fraction of $\mathrm{CO}_{2}$ in the carbonization acceleration test is $20 \%$, the test object is mainly the test specimen which has undergone 28 days of standard curing. The effect of 14 and 28 days of carbonization acceleration is equivalent to that of 26 and 51 years of natural carbonization respectively [1]. A lot of researchers have researched $\mathrm{CO}_{2}$-erosion of cement-based materials with the carbonization acceleration method and have established a corresponding structure service life prediction model [2-4].

Mineral admixtures have increasingly become indispensable components in cementbased material. Research of the durability of cement-based materials mixed with mineral admixture in the carbonization context has been the research hotspot at home and abroad [5-8]. Abid et al. [9] researched the influence of $\mathrm{CO}_{2}$ saturated water on cementbased materials, finding that influences of erosion on the porosity at the early stage and at the late stage are different. Mo and Zhang et al. $[10,11]$ think that mineral admixtures can be used to improve the performance of concrete, including fly ash and Ground Granulated Blast Furnace Slag (GGBS). Wen et al. [12] carried research, finding that the erosion influence of $\mathrm{CO}_{2}$ on concrete mixed with a large number of mineral admixtures in the 
carbonization context is more complicated than ordinary concrete and the $\mathrm{CO}_{2}$ erosion influence on concrete with different degrees of maturity and exposed to a carbonization environment is significantly different. Czarnecki et al. [13] think that carbonization of cement-based materials mixed with mineral admixtures is more complicated, that is, after cement is replaced by a lot of mineral admixtures, the compaction of the set cement structure can be improved under the volcanic ash effect, but the hydration process is relatively slow, it influences limited improvement on concrete with a low curing age and will significantly reduce the quantity of effective alkali in the set cement and the anticarbonization capability of cement-based material at the early stage declines significantly. However, in practical engineering, mold is disassembled only several days after pouring of cement-based materials and it is usually required that cement-based materials mixed with admixtures should undergo 14 days of curing. Compared with 28 days of standard curing, cement-based materials have contacted with $\mathrm{CO}_{2}$ in the air much earlier than the standard time. It can be seen that it is hard to safely, accurately and effectively predict the service life of cement-based materials mixed with mineral admixtures exposed to the carbonization environment at an early time with the carbonization prediction model of the curing age of 28 days.

In the meanwhile, according to relevant data [14], the concentration of $\mathrm{CO}_{2}$ in the air has increased by $25 \%$ over the last 100 years; it is predicted that the average concentration in 2100 will increase from the current 379 to $650 \mathrm{ppm}$, and the service environment of cement-based materials will be severer. As the concentration of $\mathrm{CO}_{2}$ in the air increases, it is urgently needed to establish a prediction model of the service life of cement-based materials mixed with mineral admixtures in the carbonization environment at an early time.

Based on the above analysis, this paper adopts 15 groups of cement mortar test specimens mixed with mineral admixtures. After 14 days of standard curing, they are put in the carbonization acceleration box to simulate the process of $\mathrm{CO}_{2}$ erosion in the carbonization environment at an early time. Through analyzing existing prediction models, the mineral admixture carbonization speed influence coefficient $\mathrm{K}_{\mathrm{m}}$ is introduced, the prediction model of service life of concrete mixed with mineral admixtures at an early time is put forward, model parameters are determined with the particle swarm optimization (PSO) method, and the established model is verified in combination with existing literature data. The research outcome is of great significance for safe application, durability design, and operation management of cement-based materials mixed with a lot of mineral admixtures.

\section{Test Scheme Design and Result Analysis}

\subsection{Raw Materials}

Raw materials used in this test include PII42.5 cement produced by Ningbo Kehuan New Building Material Co., Ltd. (Ningbo, China), class-II Fly ash provided by China Guodian Beilun Power Plant (Ningbo, China), S95 slag powder processed by Ningbo Gangxin Building Material Technology Co., Ltd. (Ningbo, China), and ISO standard sand produced by Xiamen ISO Standard Sand Co., Ltd. (Xiamen, China).

\subsection{Test Design}

Cement, coal ash, mineral powder and sand are poured into the blender at the ratio as shown in Table 1 by the author designed for even mixing, and water is added for mixing, then, the mixture is put in a test mold $(100 \mathrm{~mm} \times 100 \mathrm{~mm} \times 100 \mathrm{~mm})$ which is put on the vibration table for vibration forming and is disassembled $24 \mathrm{~h}$ later. The test is put in a standard curing box (temperature of $(20 \pm 2)^{\circ} \mathrm{C}$, humidity above $\left.90 \%\right)$ for curing. After curing for 14 days, it is taken out and dried it at room temperature for 1 day, and then five surfaces (excluding the formed surface) of the test specimen are processed with wax sealing. At last, the specimen is transferred into the carbonization test box for the erosion acceleration test. The temperature in the box shall be $(20 \pm 2)^{\circ} \mathrm{C}$ constantly, the volume fraction of $\mathrm{CO}_{2}$ is $(20 \pm 3) \%$, and the relative humidity is $(70 \pm 5) \%$. The numerical value of the cylinder pressure gauge as well as the temperature and humidity of the box 
are checked regularly. This test is used to simulate the working condition of engineering after 14 days of standard curing of cement-based materials mixed with mineral admixtures. After reaching the corresponding erosion age, the core of the test specimen is taken out, $\mathrm{pH}$ indicator is sprayed on the fresh cross section, and the carbonization depth is measured with the vernier gauge. Please see Table 1 for the results.

Table 1. Mix proportions of mineral admixture cement based materials and carbonation depth.

\begin{tabular}{|c|c|c|c|c|c|c|c|c|c|c|c|}
\hline \multirow[b]{2}{*}{ Specimen } & \multicolumn{2}{|c|}{ Dosage/\% } & \multirow{2}{*}{$\begin{array}{c}\text { Cement } \\
{[\mathrm{g}]}\end{array}$} & \multirow{2}{*}{$\begin{array}{c}\text { Binding } \\
\text { Material [g] }\end{array}$} & \multirow{2}{*}{$\begin{array}{l}\text { Water } \\
{[\mathrm{g}]}\end{array}$} & \multirow{2}{*}{$\begin{array}{c}\text { Sand } \\
{[g]}\end{array}$} & \multirow[b]{2}{*}{ W/B } & \multicolumn{4}{|c|}{ Carbonation Depth [mm] } \\
\hline & Fly Ash & Slag & & & & & & $\begin{array}{c}3 \\
\text { Days }\end{array}$ & $\begin{array}{c}7 \\
\text { Days }\end{array}$ & $\begin{array}{c}14 \\
\text { Days }\end{array}$ & $\begin{array}{c}28 \\
\text { Days }\end{array}$ \\
\hline FC101 & 25 & 0 & 540 & 720 & 288 & 1800 & 0.4 & 0.1 & 0.4 & 1.0 & 1.5 \\
\hline FC102 & 35 & 0 & 468 & 720 & 288 & 1800 & 0.4 & 0.3 & 0.6 & 1.8 & 3.0 \\
\hline FC103 & 45 & 0 & 396 & 720 & 288 & 1800 & 0.4 & 0.3 & 1.0 & 2.4 & 3.9 \\
\hline FC201 & 25 & 0 & 540 & 720 & 360 & 1800 & 0.5 & 0.5 & 1.2 & 3.2 & 4.5 \\
\hline FC202 & 35 & 0 & 468 & 720 & 360 & 1800 & 0.5 & 1.1 & 3.5 & 4.0 & 4.3 \\
\hline FC203 & 45 & 0 & 396 & 720 & 360 & 1800 & 0.5 & 1.8 & 3.6 & 7.6 & 11.0 \\
\hline FC301 & 25 & 0 & 540 & 720 & 432 & 1800 & 0.6 & 1.4 & 4.5 & 6.4 & 12.0 \\
\hline FC302 & 35 & 0 & 468 & 720 & 432 & 1800 & 0.6 & 1.6 & 4.5 & 7.8 & 15.4 \\
\hline FC303 & 45 & 0 & 396 & 720 & 432 & 1800 & 0.6 & 2.0 & 8.2 & 13.0 & 19.0 \\
\hline SC1 & 0 & 30 & 504 & 720 & 360 & 1800 & 0.5 & - & 0.1 & 0.3 & 0.6 \\
\hline SC2 & 0 & 40 & 432 & 720 & 360 & 1800 & 0.5 & 0.1 & 0.4 & 1.0 & 1.4 \\
\hline SC3 & 0 & 50 & 360 & 720 & 360 & 1800 & 0.5 & 0.7 & 1.3 & 2.7 & 3.9 \\
\hline FSC1 & 25 & 30 & 324 & 720 & 360 & 1800 & 0.5 & 1.6 & 2.8 & 4.5 & 5.3 \\
\hline FSC2 & 35 & 40 & 180 & 720 & 360 & 1800 & 0.5 & 1.5 & 2.4 & 3.9 & 4.4 \\
\hline FSC3 & 45 & 50 & 36 & 720 & 360 & 1800 & 0.5 & 6.4 & 13.5 & 18.9 & 30.9 \\
\hline
\end{tabular}

\subsection{Results and Discussion}

It can be seen from the test results in Table 1 that the carbonation depth of $45 \%$ fly ash concrete is 2.6 times that of $25 \%$ when the water cement ratio and carbonation time of FC101 and FC103 are the same; the carbonation depth of $45 \%$ fly ash concrete is 2.4 times that of 25\% when the water cement ratio and carbonation time of FC201 and FC203 are the same. These show that the depth of $\mathrm{CO}_{2}$-erosion increases with the increase of fly ash content.

Compared with SC1 SC3, under the same water cement ratio, the 28 days carbonation depth of $40 \%$ mineral powder concrete is 2.3 times that of $30 \%$ under the same conditions, and the 28 days carbonation depth of $50 \%$ mineral powder concrete is 6.5 times that of $30 \%$ under the same conditions. These show that the carbonation depth begins to increase with the increase of mineral powder content, and the growth range of carbonation depth obviously increases with the increase of mineral powder content.

By comparing FC201 FC203, SC1 SC3 and FSC1 FSC3, it is found that the carbonation depth of concrete is larger than that of single action when adding fly ash and mineral powder in the same condition. In addition, carbonation depth is also affected by water cement ratio and cement dosage.

\section{Establishment of a Practical Prediction Model}

\subsection{Existing Model Evaluation}

Carbonization of cement-based materials means that $\mathrm{CO}_{2}$ in the environment spreads into cement-based materials and reacts with alkali substances in pores to reduce the alkalinity of cement-based materials [15]. Spread of $\mathrm{CO}_{2}$ inside cement-based materials follows Fick's First Law, and its erosion depth is proportional to the square root of the erosion time.

The erosion speed of $\mathrm{CO}_{2}$ in cement-based materials is mainly affected by $\mathrm{CO}_{2}$ spread speed, the content of active substances which can react with $\mathrm{CO}_{2}$ in the unit volume of cement-based materials and the erosion time. The spread speed of $\mathrm{CO}_{2}$ is related to the 
pore structure of hardened cement-based materials, and the content of active substances which can react with $\mathrm{CO}_{2}$ in the unit volume of cement-based materials is affected by the hydration degree and cement consumption. Existing prediction models of carbonization service life of cement-based materials are analyzed. The mainparameters considered are as shown in Table 2.

Table 2. Mostly considered factors in the existing models.

\begin{tabular}{ccccc}
\hline Model & W/C & Kind of Cement & Proportion of Cement & Mineral Admixtures \\
\hline Zhu A.M. [16] & Y & Y & - & - \\
Di X.T. [16] & Y & - & Y & Only the influence of fly ash is considered \\
Gong L.S. [16] & Y & Y & Y & - \\
Huang S.Y. [16] & Y & Y & Y & \\
\hline
\end{tabular}

Huang S.Y. model [16] is as follows:

$$
\begin{aligned}
& \mathrm{W} / \mathrm{C}>0.6, \mathrm{X}_{\mathrm{c}}=104.27 \cdot \mathrm{K} \cdot \mathrm{K}_{\mathrm{c}}{ }^{0.54} \cdot \mathrm{K}_{\mathrm{w}}{ }^{0.47} \cdot \sqrt{t} \\
& \mathrm{~W} / \mathrm{C} \leq 0.6, \mathrm{X}_{\mathrm{c}}=73.54 \cdot \mathrm{K} \cdot \mathrm{K}_{\mathrm{c}}{ }^{0.83} \cdot \mathrm{K}_{\mathrm{w}}{ }^{0.13} \cdot \sqrt{t}
\end{aligned}
$$

where $\mathrm{K}$ is the influence coefficient of the cement variety. It is 1.0 for ordinary silicate cement, 1.43 for cement mixed with slag, 1.56 for silicate cement mixed with coal ash, and 1.78 for slag cement mixed with coal ash. $\mathrm{K}_{\mathrm{c}}$ is the influence coefficient of cement consumption, $\mathrm{K}_{\mathrm{C}}=(-0.0191 \mathrm{C}+9.311) \times 10^{-3}$, and $\mathrm{C}$ is the proportion of cement in cementing materials; $\mathrm{K}_{\mathrm{W}}$ is the influence coefficient of water-cement ratio, $\mathrm{K}_{\mathrm{w}}=(9.844 \mathrm{~W} / \mathrm{C}-2.982) \times 10^{-3}$; $t$ is the carbonization time, year and $\mathrm{W} / \mathrm{C}$ is the water-cement ratio;

The Gong Luoshu model [16] is as follows:

$$
\mathrm{X}_{\mathrm{c}}=\mathrm{K}_{\mathrm{w}} \mathrm{K}_{\mathrm{c}} \mathrm{K}_{\mathrm{g}} \mathrm{K}_{\mathrm{FA}} \mathrm{K}_{\mathrm{b}} \mathrm{K}_{\mathrm{r}} a \sqrt{t}
$$

where $X_{c}$ is the carbonization depth, $\mathrm{mm}$; $a$ is the carbonization coefficient which is 2.32 for ordinary concrete and 4.18 for lightweight aggregate concrete; $t$ is the carbonization time, year; $\mathrm{K}_{\mathrm{w}}, \mathrm{K}_{\mathrm{c}}, \mathrm{K}_{\mathrm{g}}, \mathrm{K}_{\mathrm{FA}}, \mathrm{K}_{\mathrm{b}}, \mathrm{K}_{\mathrm{r}}$ represent the water-cement ratio, cement consumption, aggregate variety, quantity of coal ash used for replacing cement, curing method and influence coefficient of cement variety respectively. Wherein, 1 is given to $K_{g}, K_{b}$, and $K_{r}$.

Zhu Anmin Model [16] mainly takes the water-cement ratio and cement variety as the main parameters of influencing $\mathrm{CO}_{2}$ erosion speed. The water-cement ratio can reflect the quality of cement-based materials and is directly related to the porosity inside cementbased materials, and cement variety is related to the content of active substances which can react with $\mathrm{CO}_{2}$ in unit volume of cement-based materials, but these parameters cannot reflect the physiochemical process of $\mathrm{CO}_{2}$ erosion of cement-based materials, and the deviation of such models in predicting the $\mathrm{CO}_{2}$ erosion depth is usually large.

The Qiu Xiaotan Model [16], Huang Shiyuan Model [16], and Gong Luoshu Model [16] take water-cement ratio and cement consumption as the main parameters of affecting the $\mathrm{CO}_{2}$ erosion speed. Cement consumption can further quantize the content of active substances which can react with $\mathrm{CO}_{2}$ in unit volume of cement-based materials. So, such models take more aspects into consideration than the Zhu Anmin Model. In addition, compared with the Qiu Xiaotan Model, Huang Shiyuan Model, and Gong Luoshu Mosel, cement variety should also be taken in into consideration on the basis of considering watercement ratio and cement consumption [16,17], and especially the Huang Shiyuan Model and Gong Luoshu Mosel also offer the influence coefficient of cement variety. Therefore, the effectiveness and applicability of the Huang Shiyuan Model and Gong Luoshu Model are compared and verified with test data of $\mathrm{CO}_{2}$ erosion acceleration of 15 groups of test specimens exposed to carbonization under four different carbonization ages at an early stage (see Table 1 for details). Figure $1 \mathrm{a}$ is the comparison result of relative error of 
the model calculation value (Huang Shiyuan Model and Gong Luoshu Model) and the test value.

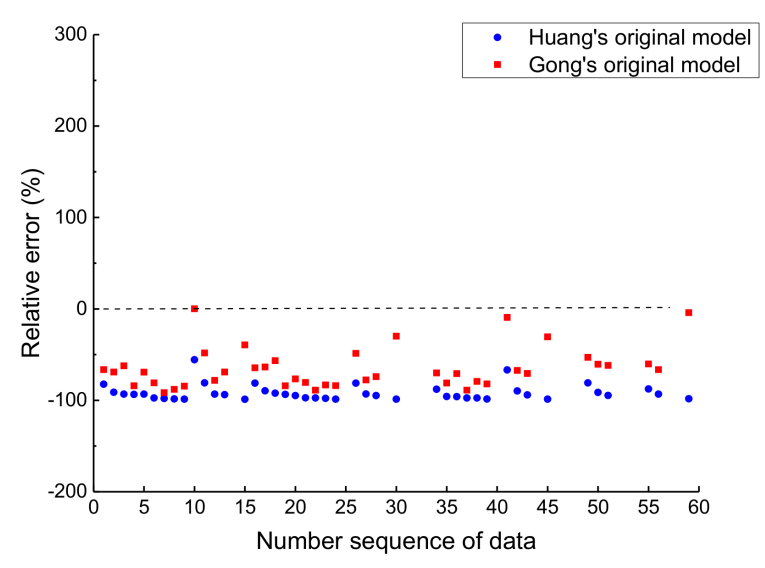

(a)

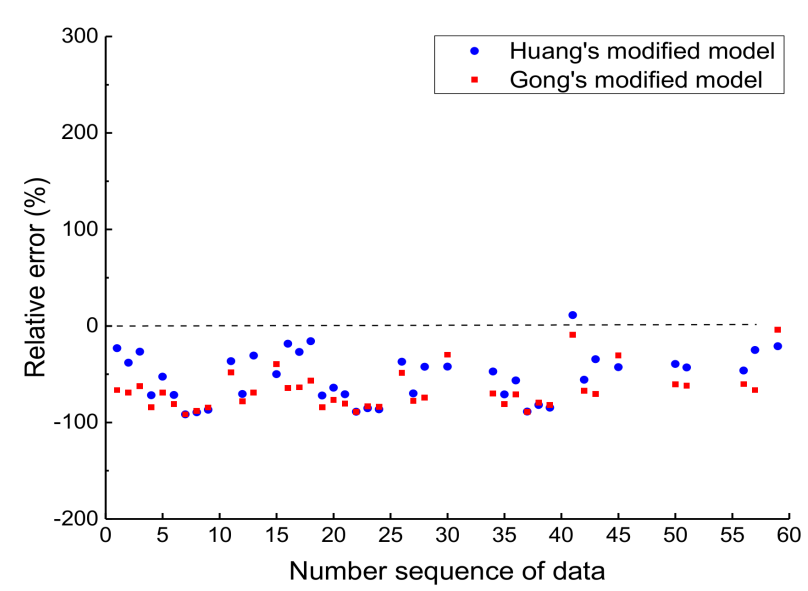

(b)

Figure 1. Comparison of relative errors between Gong L.S. model and Huang S.Y. model: (a) Original model; (b) Correction model.

According to Figure 1a, the difference between values of two models and the actual test values is relatively large, and most relative errors are around $-100 \%$. The reasons are as follows: on one hand, the above models take into consideration the influence coefficient of cement variety, and cement admixture and concrete admixtures have an intersection, but two models have significant differences [18]. For example, the specific surface area of cement admixture is usually about $330-380 \mathrm{~m}^{2} / \mathrm{kg}$, but this number for concrete admixtures is above $400-450 \mathrm{~m}^{2} / \mathrm{kg}$. On the other hand, the Gong Luoshu Model and Huang Shiyuan Model are the result of analyzing the result of carbonization test of cement-based materials after 28 days of standard curing. As regards cement-based materials mixed without admixtures or with only a few of admixtures, it does not have great influences on prediction of the service life of materials in the carbonization environment; but, as regards test specimens mixed with a large number of mineral admixtures, such as coal ash, mineral powder, etc., the hydration process is relatively slow, so the deviation will be large when predicting the service life of cement-based materials in the carbonization environment at an early stage with the above models.

In order to highlight the great influences of mineral admixtures on $\mathrm{CO}_{2}$ erosion of cement-based materials and improve the accuracy of prediction of service life of cementbased materials mixed with admixtures in the carbonization environment, researchers put forward the admixture carbonization speed influence coefficient $K_{m}$ [19-21], and Zhang Chengzhong et al. [21] put forward the corresponding expression formula (Formula (4)).

$$
\mathrm{K}_{\mathrm{m}}=\left(1+1.547 R_{f}\right) \cdot\left(1+0.768 R_{s}\right)
$$

where $R_{f}$ and $R_{s}$ are the mass percentage of coal ash and mineral powder in cementing materials.

So, $\mathrm{K}_{\mathrm{m}}$ and its expression formula are introduced into the Gong Luoshu Model and Huang Shiyuan Model to make improvement. Wherein after correction, Huang Shiyuan Model becomes:

$$
\mathrm{W} / \mathrm{C} \leq 0.6, \mathrm{X}_{\mathrm{c}}=73.54 \cdot \mathrm{K}_{\mathrm{c}}^{0.83} \cdot \mathrm{K}_{\mathrm{w}}{ }^{0.13} \cdot \mathrm{K}_{\mathrm{m}}{ }^{4.5} \cdot \sqrt{t}
$$

where $\mathrm{K}$ is the influence coefficient of the cement variety. It is 1.0 for ordinary silicate cement, 1.43 for cement mixed with slag, 1.56 for silicate cement mixed with coal ash, and 1.78 for slag cement mixed with coal ash. $\mathrm{K}_{\mathrm{c}}$ is the influence coefficient of cement consumption, 
$\mathrm{K}_{\mathrm{c}}=(-0.0191 \mathrm{C}+9.311) \times 10^{-3}$, and $\mathrm{C}$ is the proportion of cement in cementing materials; $\mathrm{K}_{\mathrm{W}}$ is the influence coefficient of water-cement ratio, $\mathrm{K}_{\mathrm{w}}=(9.844 \mathrm{~W} / \mathrm{C}-2.982) \times 10^{-3}$ and $\mathrm{W} / \mathrm{C}$ is the water-cement ratio; $t$ is the carbonization time, year.

After correction, the Gong Luoshu Model becomes:

$$
\mathrm{X}_{\mathrm{c}}=\mathrm{K}_{\mathrm{w}} \mathrm{K}_{\mathrm{c}} \mathrm{K}_{\mathrm{g}} \mathrm{K}_{\mathrm{m}} \mathrm{K}_{\mathrm{r}} a \sqrt{t}
$$

where $X_{c}$ is the carbonization depth, $\mathrm{mm}$; $a$ is the carbonization coefficient (2.32); $t$ is the carbonization time, year; $\mathrm{K}_{\mathrm{w}}, \mathrm{K}_{\mathrm{c}}, \mathrm{K}_{\mathrm{g}}, \mathrm{K}_{\mathrm{b}}$, and $\mathrm{K}_{\mathrm{r}}$ represent the water-cement ratio, cement consumption, aggregate variety, curing method and influence coefficient of cement variety, respectively; 1 is given to $\mathrm{K}_{\mathrm{g}}, \mathrm{K}_{\mathrm{b}}$, and $\mathrm{K}_{\mathrm{r}}$.

According to Figure $1 \mathrm{~b}$, the relative error between values of the modified Gong Luoshu Model and Huang Shiyuan Model and test values is decreased, but the accuracy is still not high. It is because the influence coefficient $\mathrm{K}_{\mathrm{m}}$ of carbonization speed of admixtures is from the carbonization acceleration test result of test specimens after 28 days of standard curing and is not suitable for the early $\mathrm{CO}_{2}$ erosion environment. But compared with the modified Gong Luoshu Model, the relative error of modified Huang Shiyuan Model is smaller and approximates to the zero line.

\subsection{Determination of Impact Factors of Models}

Based on the above analysis and Huang Shiyuan Model, influence coefficient $\mathrm{K}_{\mathrm{c}}, \mathrm{K}_{\mathrm{w}}$, and $\mathrm{K}_{\mathrm{m}}$ are modified. According to the early research outcome, the quantity of coal ash mixed in cement-based materials exposed to the carbonization environment approximately has a linear relationship with the $\mathrm{CO}_{2}$ erosion depth in cement-based materials, and the quantity of coal ash mixed in cement-based materials approximately has an exponential relationship with the $\mathrm{CO}_{2}$ erosion depth, so the function of $\mathrm{CO}_{2}$ erosion influence coefficient of admixtures is preliminarily determined as follows:

$$
\mathrm{K}_{\mathrm{m}}=\left(\mathrm{B}+\mathrm{b} \times R_{F}\right) \times\left(\mathrm{C}+\mathrm{c}^{R s}\right)
$$

where $\mathrm{B}, \mathrm{C}, \mathrm{b}$ and $\mathrm{c}$ are unknown coefficients, and $R_{F}$ and $R_{S}$ represent the percentage of coal ash and slag in the mass of cementing materials.

\subsection{Establishment and Correction of the Prediction Model}

This paper also proposes the new prediction model of service life of cement-based materials mixed with a large number of mineral admixtures in the carbonization environment at an early time (hereinafter referred to as "proposed model"):

$$
\begin{aligned}
& \mathrm{W} / \mathrm{C} \leq 0.6, \mathrm{X}_{\mathrm{c}}=73.54 \cdot \mathrm{K}_{\mathrm{c}}{ }^{\mathrm{d}} \cdot \mathrm{K}_{\mathrm{w}}{ }^{\mathrm{e}} \cdot \mathrm{K}_{\mathrm{m}}{ }^{\mathrm{a}} \cdot \sqrt{t} \\
& \mathrm{~W} / \mathrm{C}>0.6, \mathrm{X}_{\mathrm{c}}=213.89 \cdot \mathrm{K}_{\mathrm{C}}{ }^{\mathrm{J}} \cdot \mathrm{K}_{\mathrm{w}}{ }^{\mathrm{k}} \cdot \mathrm{K}_{\mathrm{m}} \cdot \sqrt{t}
\end{aligned}
$$

where $K_{c}$ is the influence coefficient of cement consumption, $K_{c}=(f \cdot C+g) \times 10^{-3}$, and $\mathrm{C}$ is the proportion of cement consumption in cementing materials; $\mathrm{K}_{\mathrm{w}}$ is the influence coefficient of water-cement ratio, $\mathrm{K}_{\mathrm{w}}=(\mathrm{h} \cdot \mathrm{W} / \mathrm{C}+\mathrm{i}) \times 10^{-3}$, and $\mathrm{W} / \mathrm{C}$ is the water-cement ratio; $\mathrm{K}_{\mathrm{m}}$ is the influence coefficient of $\mathrm{CO}_{2}$ erosion of admixture; $t$ is the carbonization time, year; and $\mathrm{d}, \mathrm{e}, \mathrm{a}, \mathrm{J}, \mathrm{k}$ and $\mathrm{L}$ are known coefficients.

By using test data of carbonization acceleration of 60 groups of cement-based materials exposed to carbonization at an early stage, the original parameter $K_{w}$ and $K_{c}$ in the Huang Shiyuan Model Formula (2) in literature [16] are input into Formula (4), fitting analysis is applied to the coefficient $\mathrm{K}_{\mathrm{m}}$ introduced into Formula (4) with PSO method [22], and then $\mathrm{K}_{\mathrm{m}}$ is input Formula (7) to get new $\mathrm{K}_{\mathrm{c}}$ and $\mathrm{K}_{\mathrm{w}}$ through fitting to get the prediction model of service life of cement-based materials mixed with a lot of admixtures in the carbonization environment at an early stage:

$$
\mathrm{W} / \mathrm{C}<0.6, \mathrm{X}_{\mathrm{c}}=73.54 \cdot \mathrm{K}_{\mathrm{c}}^{0.628} \cdot \mathrm{K}_{\mathrm{w}}{ }^{0.105} \cdot \mathrm{K}_{\mathrm{m}}{ }^{4.30} \cdot \sqrt{t}
$$


where $\mathrm{K}_{\mathrm{c}}$ is the influence coefficient of cement consumption, $\mathrm{K}_{\mathrm{c}}=(-0.0055 \mathrm{C}+2.07) \times 10^{-3}$, and $\mathrm{C}$ is the percentage of cement in consumption of cementing materials; $\mathrm{K}_{\mathrm{w}}$ is the influence coefficient of water-cement ratio, $\mathrm{K}_{\mathrm{w}}=(5.49 \mathrm{~W} / \mathrm{C}-2.196) \times 10^{-3}$, and W/C is the water-cement ratio; $\mathrm{K}_{\mathrm{m}}$ is the influence coefficient of $\mathrm{CO}_{2}$ erosion of admixtures, $\mathrm{K}_{\mathrm{m}}=\left(0.466+0.983 R_{f}\right) \cdot\left(1.824+2.711 R_{s}\right), R_{f}$ and $R_{s}$ are the percentage of the mass of coal ash and the mass of mineral powder in the mass of cementing material; and $t$ is the carbonization time, year.

Similarly, the prediction model of service life of cement-based materials mixed with a lot of mineral admixtures in the carbonization environment at an early stage is as follows:

$$
\mathrm{W} / \mathrm{C} \geq 0.6, \mathrm{X}_{\mathrm{c}}=213.89 \cdot \mathrm{K}_{\mathrm{c}}^{0.83} \cdot \mathrm{K}_{\mathrm{w}}{ }^{0.13} \cdot \mathrm{K}_{\mathrm{m}}^{2.317} \cdot \sqrt{t}
$$

where $K_{c}$ is the influence coefficient of cement consumption, $K_{c}=(-0.0191 C+9.311) \times 10^{-3}$, and $\mathrm{C}$ is the percentage of cement in consumption of cementing materials; $\mathrm{K}_{\mathrm{w}}$ is the influence coefficient of water-cement ratio, $\mathrm{K}_{\mathrm{w}}=(9.844 \mathrm{~W} / \mathrm{C}-2.982) \times 10^{-3}$, and W/C is the water-cement ratio; $\mathrm{K}_{\mathrm{m}}$ is the influence coefficient of $\mathrm{CO}_{2}$ erosion of admixtures, $\mathrm{K}_{\mathrm{m}}=\left(1+4.4236 R_{f}\right) \cdot\left(1.7747 R_{s}+1\right)$; and $t$ is the carbonization time, year.

\subsection{Model Comparison and Verification}

Figure 2 is the comparison result of the relative error of the model calculation value and the test value. Table 3 is the mean value and standard deviation of relative errors of the model. It can be seen that point distribution of the proposed model more approximates to the zero line, the mean value, and standard deviation of relative errors are the smallest, and its effectiveness and practicability are better than the modified Huang Shiyuan Model and Modified Gong Luoshu Model.

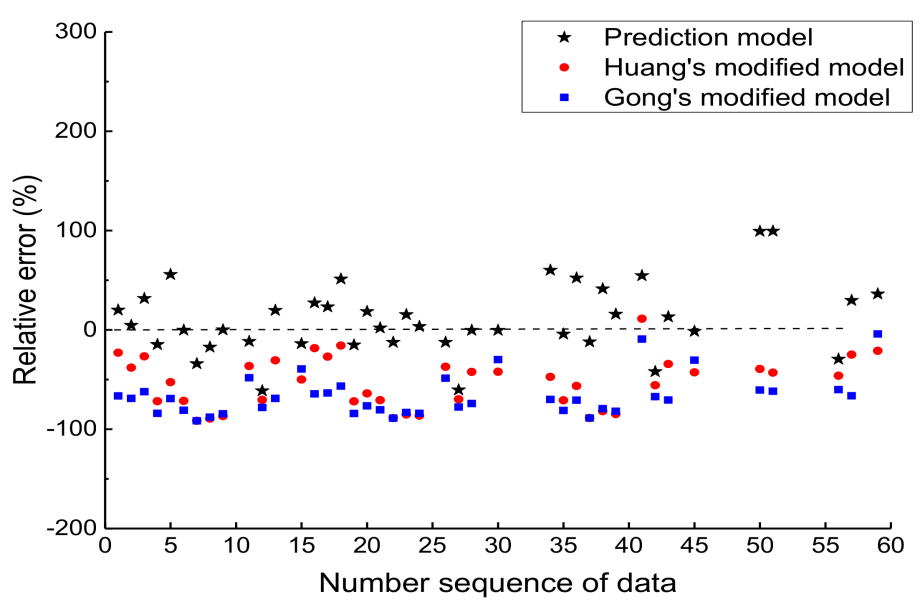

Figure 2. Comparison of relative errors between modified existing models and proposed model.

Table 3. Comparison of Relative Errors of Three Models.

\begin{tabular}{cccc}
\hline Relative Errors & $\begin{array}{c}\text { Modified Gong } \\
\text { Luoshu Model }\end{array}$ & $\begin{array}{c}\text { Modified Huang } \\
\text { Shiyuan Model }\end{array}$ & Proposed Model \\
\hline Mean value & 0.458 & 0.374 & 0.189 \\
Standard deviation & 0.353 & 0.319 & 0.241 \\
\hline
\end{tabular}

In order to further discuss the accuracy and applicability of the proposed model, the paper adopts data of $\mathrm{CO}_{2}$ erosion of cement-based materials mixed with mineral admixtures exposed to carbonization environment for less than 14 days of standard curing in literature [23] to carry out verification. See Table 4 for the comparison of ratio of the test value and the calculation value of the proposed model. In the formula, $R_{\mathrm{W} / \mathrm{C}}$ is the 
water-cement ratio, $\beta_{\mathrm{f}}$ is the quantity of mixed coal ash, $\beta_{\mathrm{bs}}$ is the quantity of mixed mineral powder, $\mathrm{T}$ is the age, $\mathrm{X}_{c} \mathrm{e}$ is the test value, and $\mathrm{Xc}_{c}^{\mathrm{P}}$ is the calculation value of the proposed model. As shown in Table 4, the mean value, standard deviation and variable coefficient of the ratio of the test value and the calculation value are $0.929,0.147$, and 0.159 , respectively. Such value reveals that test values and calculation values are relatively consistent, and their discreteness is relatively small.

Table 4. Comparisons between calculation values of the prediction model and other experimental values.

\begin{tabular}{|c|c|c|c|c|c|c|c|c|}
\hline No. & $B /\left(\mathrm{kg} / \mathrm{m}^{3}\right)$ & $\mathbf{R}_{\mathbf{W} / \mathrm{C}}$ & $\beta_{\mathrm{f}} / \%$ & $\beta_{\mathrm{bs}} / \%$ & $\mathrm{~T} / \mathrm{d}$ & $\mathrm{X}_{\mathrm{C}}^{\mathrm{e}} / \mathrm{mm}$ & $\mathrm{X}_{\mathrm{C}}^{\mathrm{P}} / \mathrm{mm}$ & $X_{C}{ }^{e} / X_{C}{ }^{P}$ \\
\hline 1 & 1560 & 0.4 & 16 & 4 & 1000 & 5.8 & 6.457 & 0.90 \\
\hline 2 & 1680 & 0.43 & 12 & 8 & 720 & 8.1 & 8.300 & 0.98 \\
\hline 3 & 1560 & 0.4 & 16 & 4 & 720 & 5.5 & 5.479 & 1.00 \\
\hline 4 & 1800 & 0.4 & 21 & 14 & 720 & 7.8 & 8.920 & 0.87 \\
\hline 5 & 1560 & 0.43 & 0 & 35 & 540 & 4.7 & 4.353 & 1.08 \\
\hline 6 & 1560 & 0.43 & 0 & 35 & 360 & 4.7 & 3.554 & 1.32 \\
\hline 7 & 1560 & 0.4 & 16 & 4 & 360 & 3.3 & 3.874 & 0.85 \\
\hline 8 & 1680 & 0.43 & 12 & 8 & 180 & 3 & 4.150 & 0.72 \\
\hline 9 & 1560 & 0.43 & 0 & 35 & 180 & 2 & 2.513 & 0.80 \\
\hline 10 & 1680 & 0.4 & 50 & 0 & 56 & 8.3 & 9.107 & 0.91 \\
\hline 11 & 1560 & 0.5 & 21 & 14 & 56 & 5.1 & 5.312 & 0.96 \\
\hline 12 & 1560 & 0.4 & 16 & 4 & 28 & 1 & 1.080 & 0.93 \\
\hline 13 & 1680 & 0.4 & 50 & 0 & 28 & 5.2 & 6.440 & 0.81 \\
\hline 14 & 1560 & 0.5 & 21 & 14 & 28 & 4 & 3.756 & 1.06 \\
\hline 15 & 1800 & 0.4 & 21 & 14 & 28 & 1.3 & 1.759 & 0.74 \\
\hline
\end{tabular}

\section{Conclusions}

- By summarizing existing cement-based material carbonization depth prediction models, mainly taking into consideration the influence of variety and consumption of mineral admixtures on carbonization of cement-based materials at an early stage, based on the existing Huang Shiyuan Model and by introducing $\mathrm{K}_{\mathrm{m}}$, the influence coefficient of $\mathrm{CO}_{2}$ erosion of admixtures, and corresponding functions, this paper proposes the prediction model of service life of cement-based materials mixed with a lot of mineral admixtures in the carbonization environment at an early stage; and the model parameters are determined with the PSO method. Compared with existing models, the prediction result of the proposed model is better consistent with the test data and has a smaller error.

- The proposed prediction model of service life of cement-based materials mixed with a lot of mineral admixtures in the $\mathrm{CO}_{2}$ erosion environment at an early stage is of great significance for safe application of cement-based materials mixed with mineral admixtures as well as design and operation management of the durability of structures.

Author Contributions: Conceptualization, X.W.; methodology, S.W.; software, J.C.; validation, S.W.; formal analysis, S.W.; investigation, S.W.; data curation, J.C.; writing-original draft preparation, J.C.; writing-review and editing, S.W.; supervision, X.W.; project administration, X.W.; funding acquisition, X.W. All authors have read and agreed to the published version of the manuscript.

Funding: This research was funded by a National Natural Science Foundation of China (Grant No. 51569035), the Major Project of "Science and Technology Innovation 2025" in Ningbo City (Grant No. 2018B10091), and the Natural Science Foundation of Zhejiang Province (Grant No. LY20E080015).

Institutional Review Board Statement: Not applicable.

Informed Consent Statement: Not applicable.

Data Availability Statement: The data used to support the findings of this study are available from the corresponding author upon request. 
Acknowledgments: This research was funded by a National Natural Science Foundation of China (Grant No. 51569035), the Major Project of "Science and Technology Innovation 2025" in Ningbo City (Grant No. 2018B10091), and the Natural Science Foundation of Zhejiang Province (Grant No. LY20E080015).

Conflicts of Interest: The authors declare no conflict of interest.

\section{References}

1. Sun, B.; Mao, S.; Wang, J.; Di, X.; Ren, R. Experimental study on correlation between natural carbonation and accel-erated carbonation of long-term observation concrete specimens. Build. Struct. 2019, 49, 111-115.

2. Qin, L.; Gao, X.; Chen, T. Influence of mineral admixtures on carbonation curing of cement paste. Constr. Build. Mater. 2019, 33, 653-662. [CrossRef]

3. Shen, Q.; Pan, G.; Zhan, H. Test method to simulate the influence of the interface on the concrete carbonation process. J. Wuhan Univ. Technol. Sci. Ed. 2016, 31, 594-598. [CrossRef]

4. Kim, T.-K.; Choi, S.-J.; Kim, J.-H.J.; Chu, Y.-S.; Yu, E. Performance Based Evaluation of Carbonation Resistance of Concrete According to Various Curing Conditions from Climate Change Effect. Int. J. Concr. Struct. Mater. 2017, 11, 687-700. [CrossRef]

5. Leemann, A.; Moro, F. Carbonation of concrete: The role of $\mathrm{CO} 2$ concentration, relative humidity and CO2 buffer capacity. Mater. Struct. 2017, 50, 30. [CrossRef]

6. Lye, C.-Q.; Dhir, R.K.; Ghataora, G.S. Carbonation resistance of GGBS concrete. Mag. Concr. Res. 2016, 68, 936-969. [CrossRef]

7. Zhou, H.; Zheng, J.; Hu, D.; Zhang, C.; Lu, J.; Gao, Y. Effect of CO2 erosion on the pore structure of cement-based materials in water soaking and moist environment. Chem. Ind. Eng. Prog. 2018, 37, 4791-4798.

8. Chen, D. Quantitative Study on Carbonization Environmental Action and Durability Design for Concrete Structure; Guangxi University: Nanning, China, 2014.

9. Abid, K.; Gholami, R.; Choate, P.; Nagaratnam, B.H. A review on cement degradation under CO2-rich environment of sequestration projects. J. Nat. Gas Sci. Eng. 2015, 27, 1149-1157. [CrossRef]

10. Mo, Z.; Gao, X.; Su, A. Mechanical performances and microstructures of metakaolin contained UHPC matrix under steam curing conditions. Constr. Build. Mater. 2021, 268, 121112. [CrossRef]

11. Zhang, J.; Chen, T.; Gao, X. Incorporation of self-ignited coal gangue in steam cured precast concrete. J. Clean. Prod. 2021, 292, 126004. [CrossRef]

12. Chen, J.; Wen, X.; He, Y.; Wang, S. Carbonation depth and prediction of concrete with high volume mineral ad-mixture. Highway 2019, 12, 230-235.

13. Czarnecki, L.; Woyciechowski, P.; Adamczewski, G. Risk of concrete carbonation with mineral industrial by-products. KSCE J. Civ. Eng. 2017, 22, 755-764. [CrossRef]

14. Zhou, H.; Zheng, J.; Hu, D.; Zhang, C.; Lu, J.; Gao, Y.; Zhang, W. Deterioration mechanism of tunnel lining structure in thecarbonated water en-vironment. Rock Soil Mech. 2019, 40, 2469-2477.

15. Liu, D.; Niu, D.; Su, L. Research progress on durability of stressed concrete under environmental actions. Eng. Mech. 2019, 36, 1-10. [CrossRef]

16. Xiao, J.; Gou, C. Review of research on concrete carbonation. Concrete 2010, 1, 40-44.

17. Chen, Z.; Hu, Y.; Zhao, Y.; Yu, B. Multi-factor Computation Model of Concrete Carbonation Depth Based on Material Parameters in Standard Carbonization Environment. Bull. Chin. Ceram. Soc. 2019, 38, 1681-1687+1693.

18. Wang, Y.; Su, Y.; Zhou, S. Cement Admixture and Concrete Admixture; Chemical Industry Publishing House: Beijing, China, 2011.

19. Kai, G.; Fei, J.; Tabbaa, A.A.; Shi, B.; Jin, L. Mechanical and hydration properties of ground granulated blastfurnace slag pastes activated with MgO-CaO mixtures. Constr. Build. Mater. 2014, 69, 101-108.

20. Suryavanshi, A.; Scantlebury, J.; Lyon, S. The binding of chloride ions by sulphate resistant portland cement. Cem. Concr. Res. 1995, 25, 581-592. [CrossRef]

21. Zhang, C.; Sun, G.; Hu, X.; Zhang, Y. Experimental study on the effect of admixtures on the early car-bonation depth of concrete Bull. Chin. Ceram. Soc. 2017, 36, 282-287.

22. Xu, Z.; Zhang, E.; Chen, Q. Rotary unmanned aerial vehicles path planning in rough terrain based on multi-objective particle swarm optimization. J. Syst. Eng. Electron. 2020, 31, 130-141. [CrossRef]

23. Jia, Y. Research on Carbonation Characteristics of High Volume Mineral Admixtures Concrete. Ph.D. Thesis, Tsinghua University, Beijing, China, 2010. 